\title{
Urinary nitrate concentration as a marker for kidney transplant rejection
}

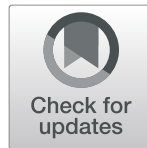

Amy Riddell ${ }^{*}$ (D) John Kirkwood ${ }^{2}$, Miranda Smallwood', Paul Winyard ${ }^{1}$, Beatrice Knight ${ }^{2}$, Lidia Romanczuk², Angela Shore ${ }^{1}$ and Mark Gilchrist ${ }^{1}$

\begin{abstract}
Background: Early identification and treatment of kidney transplant rejection episodes is vital to limit loss of function and prolong the life of the transplanted kidney and recipient. Current practice depends on detecting a creatinine rise. A biomarker to diagnose transplant rejection at an earlier time point than current practice, or to inform earlier decision making to biopsy, could be transformative.

It has previously been shown that urinary nitrate concentration is elevated in renal transplant rejection. Nitrate is a nitric oxide (NO) oxidation product. Transplant rejection upregulates NO synthesis via inducible nitric oxide synthase leading to elevations in urinary nitrate concentration. We have recently validated a urinary nitrate concentration assay which could provide results in a clinically relevant timeframe. Our aim was to determine whether urinary nitrate concentration is a useful tool to predict renal transplant rejection in the context of contemporary clinical practice.

Methods: We conducted a prospective observational study, recruiting renal transplant participants over an 18month period. We made no alterations to the patients' clinical care including medications, immunosuppression, diet and frequency of visits. We collected urine samples from every clinical attendance. We assessed the urinary nitrate to creatinine ratio (UNCR) between patient groups: routine attendances, biopsy proven rejection, biopsy proven no rejection and other call backs. UNCR was examined over time for those with biopsy proven transplant rejection. These four groups were compared using an ANOVA test.
\end{abstract}

Results: A total of 2656 samples were collected. UNCR during biopsy proven rejection, $n=15$ (median $49 \mu \mathrm{mol} /$ mmol, IQR 23-61) was not significantly different from that of routine samples, $n=164$ (median $55 \mu \mathrm{mol} / \mathrm{mmol}$, IQR 37-82) ( $p=0.55$ ), or biopsy proven no rejection, $n=12$ (median $39 \mu \mathrm{mol} / \mathrm{mmol}, \mathrm{IQR} 21-89)(P=0.77)$.

Overall UNCR was highly variable with no diagnostic threshold for kidney transplant rejection. Furthermore, withinpatient UNCR was highly variable over time, and thus it was not possible to produce individualised patient thresholds to identify rejection. The total taking Tacrolimus was 204 patients, with no statistical difference between the UNCR of all those on Tacrolimus, against those not, $p=0.18$.

Conclusion: The urinary nitrate to creatinine ratio is not a useful biomarker for renal transplant rejection.

Keywords: Kidney, Transplant, Nitrate, Biomarker, Rejection

\footnotetext{
* Correspondence: Amy.Riddell@nhs.net

${ }^{1}$ Institute of Biomedical and Clinical Sciences, University of Exeter, and NIHR Exeter Clinical Research Facility, Exeter, Devon, UK

Full list of author information is available at the end of the article
}

C The Author(s). 2020 Open Access This article is licensed under a Creative Commons Attribution 4.0 International License, which permits use, sharing, adaptation, distribution and reproduction in any medium or format, as long as you give appropriate credit to the original author(s) and the source, provide a link to the Creative Commons licence, and indicate if changes were made. The images or other third party material in this article are included in the article's Creative Commons licence, unless indicated otherwise in a credit line to the material. If material is not included in the article's Creative Commons licence and your intended use is not permitted by statutory regulation or exceeds the permitted use, you will need to obtain permission directly from the copyright holder. To view a copy of this licence, visit http://creativecommons.org/licenses/by/4.0/ The Creative Commons Public Domain Dedication waiver (http://creativecommons.org/publicdomain/zero/1.0/) applies to the data made available in this article, unless otherwise stated in a credit line to the data. 


\section{Background}

Kidney transplant rejection remains a problem contributing to graft loss. It is typically asymptomatic making early diagnosis difficult. Transplanted kidneys remain at risk of rejection despite significant advancements in immunosuppresion [1]. Early identification and treatment of rejection episodes is necessary to limit loss of function and prolong the life of the transplanted kidney and recipient $[2,3]$. Current practice depends on detecting a creatinine rise. Consequently, graft dysfunction and damage are likely by the time of kidney transplant biopsy and subsequent treatment [3]. A biomarker to diagnose transplant rejection at an earlier time point than current practice, or to inform earlier decision making to biopsy, could be transformative.

In 1996 Smith et al. [4] provided evidence that urinary nitrate concentration is elevated during kidney transplant rejection when compared with urinary tract infection or a non-rejection state. The same group replicated these findings showing that urinary nitrate concentration was elevated up to 5 days before a biopsy diagnosis of rejection was made [5]. It has been demonstrated that urinary nitrate concentration increases as a result of an increased expression of inducible nitric oxide synthase (iNOS) leading to increased production of nitric oxide (NO) in the transplanted organ [6, 7]. This NO is then rapidly metabolised to its stable oxidation product, nitrate. Also, in 1996 Mugge et al. [8] discovered similar findings in their cardiac transplant patients. An increased urinary nitrate concentration was noted with moderate/severe cardiac transplant rejection compared with no rejection, however this only reached statistical significance when a small group of patients who had repeated biopsies were considered separately [8].

Historically the measurement of nitrate in biological fluids has been fraught with problems [9], not least of which is the time taken to generate a result. This likely precluded progression of the work by early pioneers in the field $[4,5,8]$. We have previously validated a spectrophotometric plate method for measurement of nitrate in urine [10] which is capable of accurately determining nitrate concentration in urine in a clinically relevant timeframe for renal transplant rejection.

We sought to determine whether urinary nitrate concentration would be a useful tool to predict renal transplant rejection in the context of current clinical practice by comparing urinary nitrate concentration from routine samples given during stable kidney transplant function with those given at times of kidney transplant rejection.

\section{Methods}

We conducted a prospective observational study collecting urine samples from kidney transplant recipients over an 18-month timeframe.
Potential participants attending the renal transplant clinic at the Royal Devon and Exeter Foundation Trust were identified by Clinicians during routine clinical care. The RDETB (Royal Devon and Exeter Tissue Bank, NIHR Exeter Clinical Research Facility) team were responsible for recruitment and data/sample collection. All participants recruited were provided with a unique study identifier (ID), and all samples and data were stored under this unique ID code for later transfer to the research team.

Renal transplant patients were recruited between April 2017 and September 2018 from the Royal Devon and Exeter Hospital Kidney unit, UK. We recruited consecutive attendees from routine transplant clinics. In addition, we targeted new renal transplant patients who are at the highest risk of rejection as well as targeting those attending for a 'call back' visit due to abnormal blood results who had not yet been recruited via the routine clinic.

\section{Exclusions}

- < 18 years old

- Unable to consent

\section{Inclusion}

- Functioning renal transplant

No changes were made to patients' clinical care by the study team including; medications, immunosuppression, diet or frequency of visits. We recorded the following data: patient age, age and type of transplant, transplant mismatch, immunosuppression, kidney function, original kidney disease, and presence of urinary tract infection (UTI).

\section{Urine collection}

Regardless of their route of recruitment, all participants provided random spot urine samples at every clinical attendance during the study timeframe, whether it be a routine clinic or a 'call back'. Urine was stored at $-80{ }^{\circ} \mathrm{C}$ prior to analysis.

- 'Routine' samples were those provided from attendance at a pre-arranged clinic appointment.

- 'Call back' samples were those received when a patient attended due to being unwell, abnormal blood result or another event.

For analysis the call back group was then further divided into - biopsy proven rejection, Biopsy proven non rejection, and all other call backs (biopsy not performed). 


\section{Urine analysis}

The spectrophotometric plate method of measuring urinary nitrate as described by Miranda et al. [10] was used. This method has previously been validated by us in urine against the gold standard ozone based chemiluminescence method [11]. The coefficient of variation of the assay was $8.5 \%[10,11]$. The lower limit of detection of the assay was $6 \mu \mathrm{M}$. For urine samples with an undetectable nitrate concentration, a value of $6 \mu \mathrm{M}$ was assigned. Creatinine was measured using the Jaffe method in the clinical biochemistry laboratory at the Royal Devon and Exeter Hospital, U.K.

We have divided our patients into 4 groups:

Routine - Consisting of patients who only ever provided 'routine samples' during the study time frame. These are the patients who have not yet had a clinical concern for possible rejection and provide data on urinary nitrate before a rise in serum creatinine.

Biopsy proven rejection - Consisting of the patients who had a biopsy which diagnosed rejection.

Biopsy proven no rejection - Consisting of patients who went on to have a biopsy which showed no rejection.

Other (Non-biopsied) Callbacks - These are the patients who were asked back to the hospital for clinical reasons, usually an abnormal creatinine. This is the start of the process which may lead to a biopsy. These patients have been kept in the analysis as they were the group who were of sufficient clinical concern to call them back but who subsequently resolved clinically and did not require a biopsy. If uNCR was to be a useful biomarker of early transplant rejection it would need to be able to discriminate between these call back patients and those which were of such clinical concern that they went on to biopsy. Our analysis of these patients would therefore be informative.
To correct for variation in urinary concentration we calculated the urinary nitrate to creatinine ratio (uNCR). This was done for every routine sample and a mean taken per patient in order that each patient only contributed 1 value to the statistical analysis. The patient mean is used here to then look for deviation from this during cases of biopsy proven rejection. This was then used to calculate the overall median for the routine group. For the biopsy patients only the uNCR on the day of biopsy was used to calculate the overall median for both the groups 'biopsy proven rejection' and 'biopsy proven not rejection'. Each overall median was then compared to the other groups. Statistical analysis was completed using an ANOVA single factor test across all four groups with statistical significance accepted if $p<0.05$.

We analysed subgroups including patient immunosuppression and presence of UTI. Our validated assay measures both urinary nitrate and urinary nitrite, taken as a whole concentration. Although measuring both, urinary nitrite concentration has been shown to be less than $10 \%$ of urinary nitrate concentration in UTI in transplant populations [4].

There is data to suggest that Immunosuppressive medications such as tacrolimus and mycophenolate can affect NOS and therefore urinary nitrate [12, 13], making it relevant to look at this data. Statistical analysis was completed using a $\mathrm{T}$-Test assuming equal variance, with statistical significance accepted if $p<0.05$.

\section{Results}

Two hundred forty-one participants were recruited and all remained in the study. A total of 2656 samples were collected. From these totals, 77 participants provided 162 samples at call back attendances, with the remainder provided from routine appointments. Twenty-seven separate patients had a biopsy performed, with 15 biopsies confirming rejection. Table 1 shows participant demographics.

Table 1 Participant demographics

\begin{tabular}{|c|c|c|c|c|c|}
\hline & & \multirow{2}{*}{$\begin{array}{l}\text { Routine } \\
(n=164)\end{array}$} & \multicolumn{3}{|l|}{ Call Backs $(n=77)$} \\
\hline & & & Rejection ( $n=15$ ) & Non-Rejection $(n=12)$ & Other call-backs $(n=50)$ \\
\hline \multirow[t]{2}{*}{ Age } & Years & 57.5 & 46 & 43 & 52 \\
\hline & & $20-76$ & $27-63$ & $20-57$ & $20-71$ \\
\hline Sex & $\% M$ & 55 & 40 & 66 & 56 \\
\hline \multirow[t]{3}{*}{ Donor type } & DCD \% & 27 & 25 & 33 & 26 \\
\hline & DBD \% & 32 & 33 & 8 & 47 \\
\hline & LKD \% & 39 & 46 & 33 & 26 \\
\hline \multirow[t]{3}{*}{ Time since transplant \% } & $<1$ yr. $\%$ & 21 & 60 & 58 & 59 \\
\hline & $1-5 \mathrm{yr} . \%$ & 41 & 13 & 25 & 22 \\
\hline & $>5 \mathrm{yr} . \%$ & 37 & 26 & 16 & 18 \\
\hline Creatinine $\mu \mathrm{mol} / \mathrm{l}$ & Mean +/- SD & $136+/-55$ & $252+/-132$ & $238+/-110$ & $147+/-61$ \\
\hline
\end{tabular}

${ }^{*} D C D$ Donation after Cardiac Death, $D B D$ Donation after Brain Death, $L K D$ Living Kidney Donation 
We found creatinine to be lower in both the Routine and Other Callback groups compared to those biopsied. This is expected from the clinical context, with routine samples being from stable patients, and the other callbacks samples being collected from those with a clinical abnormality detected but who did not continue onto biopsy. The patients in the Other Callbacks Group are therefore likely to include those patients with a lower creatinine rise when compared with those who went on to be biopsied.

Urinary nitrate data is shown in Table 2. The uNCR did not differ across the four patient groups $p=0.98$. The median uNCR ( $\mu \mathrm{mol} / \mathrm{mmol})$ for the Routine Group of patients was 55.44, IQR 37-87, the Biopsy proven rejection Group 49.65, IQR 23-61, the Biopsy proven no rejection Group 39.79, IQR 21-89, and the Other Callbacks Group 41.18, IQR 26-65 (Table 3 and Fig. 1). We analysed the within patient results for all samples provided by those patients with biopsy proven rejection and the uNCR did not appear to be different at the time of biopsy compared with routine samples (Fig. 2 and Table 4).

In the Other Callback Group only 6 patients had an MSU proven urinary tract infection (UTI). No patients in either of the biopsy groups had an MSU proven UTI. The uNCR results from the time of UTI are not significantly different from those without UTI.

Table 5 shows the total proportion of patients receiving Tacrolimus $(n=204)$ was $83,93,91.6$ and $88 \%$ in groups Routine, Biopsy proven rejection, Biopsy proven no rejection and Other Callbacks respectively. There was no statistical difference between the uNCR of all those on Tacrolimus, using all groups together, against those not, $p=0.18$ (T test). For those taking Tacrolimus alone, the median $\mathrm{uNCR}(\mu \mathrm{mol} / \mathrm{mmol})$ in the Routine Group samples was 53.31, IQR 38.5-81.1, for the Biopsy proven rejection Group 26.69, IQR 19.9-35.1, for the Biopsy proven no rejection Group 59.99, IQR 21.66-168, and for the Other Callback Group 47.01, IQR 26.7-74.99. Similarly, for those taking both Tacrolimus and Mycophenolate the uNCR $(\mu \mathrm{mol} / \mathrm{mmol})$ in the Groups were: Routine samples 56.85, IQR 36.6-89.68, Biopsy proven

Table 2 Urinary nitrate $(\mu \mathrm{M})$ concentration according to group

\begin{tabular}{lllll}
\hline $\begin{array}{l}\text { Urinary Nitrate } \\
(\boldsymbol{\mu m o l / l )}\end{array}$ & $\begin{array}{l}\text { Routine } \\
(\boldsymbol{n}=\mathbf{1 6 4})\end{array}$ & $\begin{array}{l}\text { Rejection } \\
(\boldsymbol{n}=\mathbf{1 5})\end{array}$ & $\begin{array}{l}\text { Non-Rejection } \\
(\boldsymbol{n}=\mathbf{1 2})\end{array}$ & $\begin{array}{l}\text { Other } \\
\text { Call-backs } \\
(\boldsymbol{n}=\mathbf{5 0})\end{array}$ \\
\hline $\begin{array}{l}\text { Median of patient } \\
\text { means }\end{array}$ & 291.14 & 160.8 & 202.54 & 258.81 \\
IQR & 250 & 289 & 197 & 273 \\
Min & 34 & 35 & 6 & 6 \\
Max & 2212 & 659 & 598 & 1144 \\
\hline
\end{tabular}

Number of samples per patient used to calculate the mean (min-max), Routine - 5 (1-33), Rejection 1, Non-rejection 1, Other callbacks 1 (1-5)
Table 3 Urinary nitrate to creatinine ratio $(\mu \mathrm{mol} / \mathrm{mmol})$ according to group

\begin{tabular}{lllll}
\hline uNCR & $\begin{array}{l}\text { Routine } \\
(\boldsymbol{n}=\mathbf{1 6 4})\end{array}$ & $\begin{array}{l}\text { Rejection } \\
(\boldsymbol{n}=\mathbf{1 5})\end{array}$ & $\begin{array}{l}\text { Non-Rejection } \\
(\boldsymbol{n}=\mathbf{1 2})\end{array}$ & $\begin{array}{l}\text { Other Call-backs } \\
(\boldsymbol{n}=\mathbf{5 0})\end{array}$ \\
\hline Median & 55.44 & 49.65 & 39.79 & 41.18 \\
IQR & 45 & 38 & 67 & 39 \\
Min & 5 & 6 & 0.7 & 0.3 \\
Max & 217 & 212 & 239 & 459 \\
\hline
\end{tabular}

rejection 49.65, IQR 23.98-87.91, Biopsy proven no rejection 53.43, IQR 39.54-86.93, Other Callbacks 41.66, IQR 24-93.01.

\section{Discussion}

This study found urinary nitrate was unable to differentiate renal transplant rejection from stable graft function or other causes of acute graft dysfunction. The UNCR results from the 15 patients who had biopsy proven rejection showed no significant difference from biopsy proven non-rejection or routine groups. The uNCR over time within the same patient showed no significant change during episodes of rejection.

This is likely to be because the biological variability of urinary nitrate is known to be very large [14-16]. The amount of nitrate appearing in the urine is dependent on kidney function [17]. In the context of acute kidney injury, changes in tubular function and glomerular filtration can be variable during different stages of injury, further altering the excretion of both nitrate and creatinine [18]. Previous studies $[15,16]$ have also shown substantial impact of diet on urinary nitrate concentration. Contrary to other studies investigating urinary nitrate concentration as a biomarker for disease e.g., Melichar et al. [19] researching inflammatory bowel disease, we did not restrict nitrate intake or exclude those not on a low nitrate diet. This was done to examine the use of urinary nitrate concentration in urgent clinical scenarios when a period of $48 \mathrm{~h}$ of a low nitrate diet would not be possible, such as here in kidney transplant rejection.

We used random spot urine samples which are familiar and acceptable to patients in the transplant setting. We have avoided the use of timed samples, which may offer a more accurate assessment [17] of uNCR, in order to be consistent with accurately assessing the use of UNCR as a biomarker in the clinically urgent setting of kidney transplant rejection.

We have shown that on an unrestricted diet and using random spot urines, urinary nitrate concentration remains hugely variable with no diagnostic threshold for rejection identifiable. Within patient values are also highly variable (Fig. 2) and unrelated to rejection status. Thus, it was not possible to produce individualised patient thresholds for rejection. 


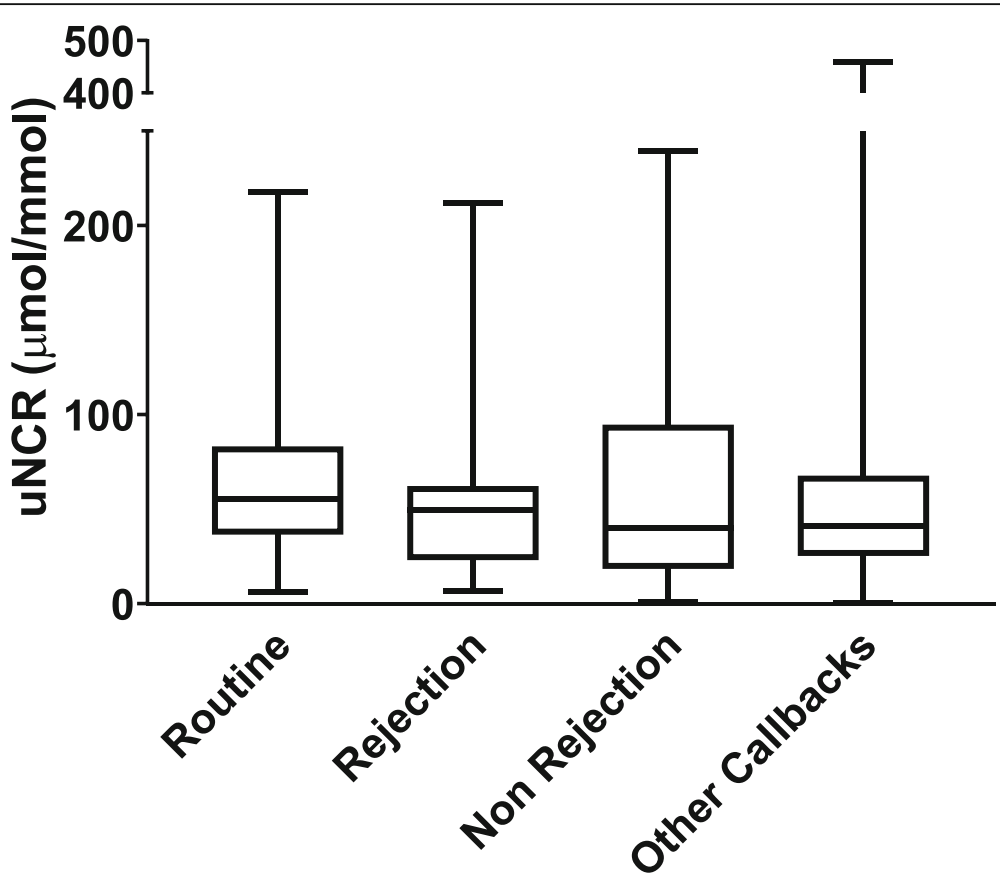

Fig. 1 Nitrate: creatinine ratio for each group; Routine, Rejection, Non-Rejection and Other Call-backs. Showing the median, IQR, maximum and minimum values for each patient group. Minimum for 'Non rejection' and 'Other call-backs were 0.73 and 0.26 respectively ( $\mu \mathrm{mol} / \mathrm{mmol}$ ). ANOVA test showed no significant difference between any groups, $p=0.98$

Our findings are notably different to the studies undertaken in this area by Smith et al. [4, 5]. In 1996 Smith et all [4] first reported that uNCR during renal transplant rejection was significantly higher than those with normal kidney function post transplantation (4937 $\mu$ mole/g during rejection versus $1585 \mu$ mole/g during stable graft function). This was also found to be associated with elevated iNOS activity (6.4 pmol citrulline/ $\mathrm{min} / \mathrm{mg}$ protein compared with 0.51$)$. Smith et al. [5] confirmed this in a second study in 2000 showing that urinary nitrate concentrations rose significantly from baseline to $4530 \mu \mathrm{M} /$ litre during the -5 to -1 days leading to a formal diagnosis of renal transplant rejection. Interestingly Mugge et al. [8] reported a uNCR of $99 \mu \mathrm{mol} / \mathrm{mmol}$ in patients without cardiac transplant rejection and $131 \mu \mathrm{mol} / \mathrm{mmol}$ in patients with moderate/ severe rejection however this difference was not significant. Mugge was only able to demonstrate a significant difference between patients with and without cardiac rejection when a small subgroup of 7 patients who had attended for repeated biopsies during the study time was analysed separately. In these patients it was found that the uNCR rose up to $99 \%$ from baseline and this value was higher, the greater the severity of rejection.

There are several potential reasons why these studies have different results to ours. Firstly, the severity of rejection is unclear from the two Smith papers. The Banff schema [3] used today was first published in 1991 and reviewed every two years thereafter. Prior to this there was no standardized, international classification for renal transplant biopsies which resulted in considerable heterogeneity. Smith et al. [4] published their first study in 1996 and do not explicitly state the criteria used for diagnosing rejection nor the grade or severity of rejection for comparison with our study. Thus, the patient cohorts studied by Smith and this paper, where levels of rejection are largely borderline, might have been substantially different.

Mugge et al. [8] showed, in a subgroup of patients who had repeated biopsies (7 patients, 48 biopsies), uNCR significantly rose by $99 \%$ during episodes of rejection with higher values for higher degrees of rejection. In our study we have 3 patients with repeated biopsies so cannot reliably assess this. From our data, we found no apparent indication that higher grades of rejection associate with increased uNCR (Table 4), though we acknowledge this is limited by low numbers. Similarly, we found no intra-patient thresholds for rejection.

Another potential difference between the present and earlier studies relates to drug effects on urinary nitrate. In this study $85 \%$ of our patient group are taking Tacrolimus with or without mycophenolate mofetil (MMF). It has been shown in animal studies that tacrolimus itself can cause a reduction in NO by reduction in endothelial nitric oxide synthase (eNOS) [12] as well as iNOS. MMF has been shown to have a similar effect [13]. Such a reduction in NO synthesis would be expected to reduce urinary 


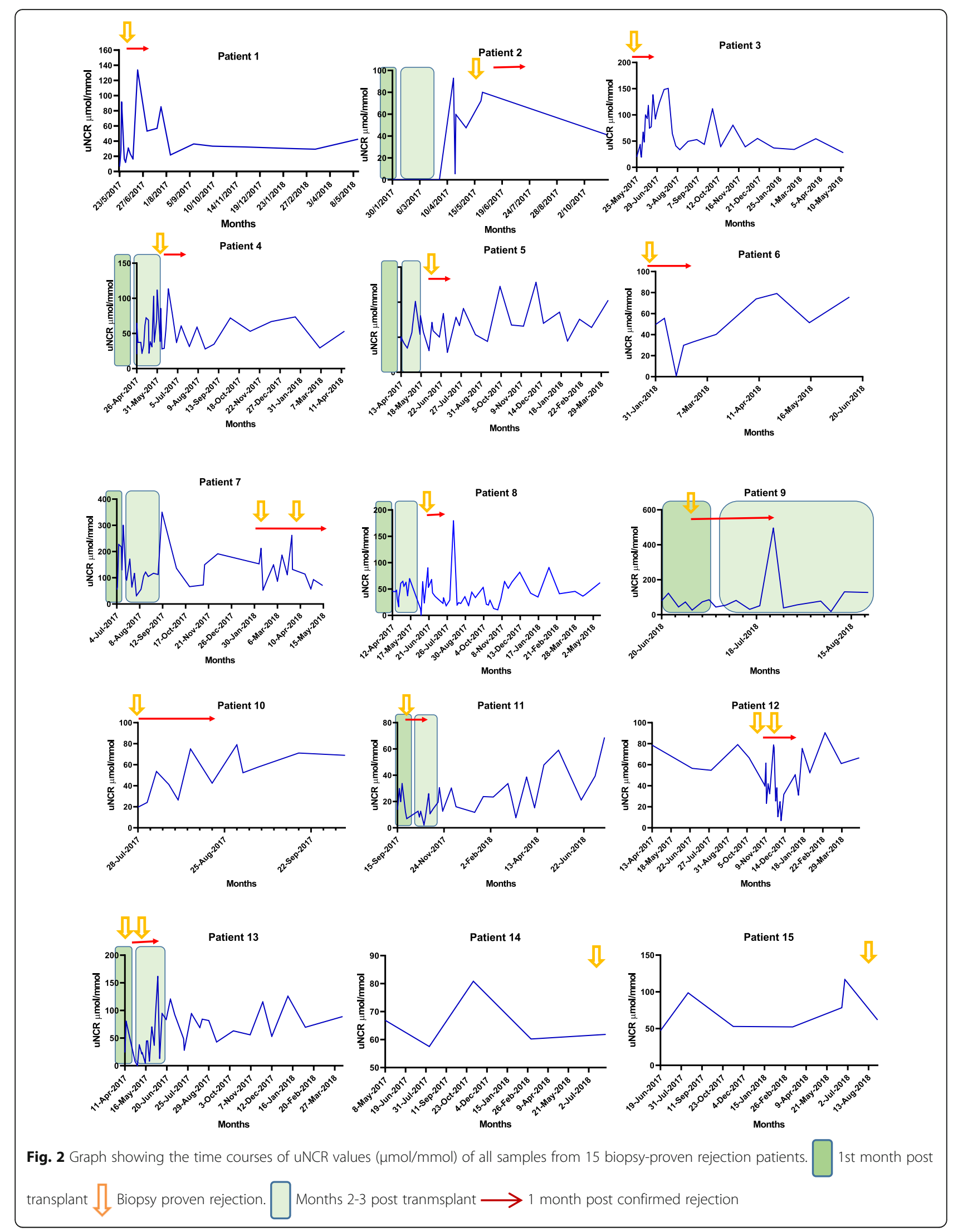


Table 415 Rejection patients; Pattern of uNCR ( $\mu \mathrm{mol} / \mathrm{mmol})$ at the time of rejection compared with all the samples they provided. Date of biopsy proven rejection. $\square$ samples within 7 days either side of the date of rejection. Graded as per Banff criteria [3]. ( $B=$ Borderline, $A B M R=$ Antibody mediated rejection)

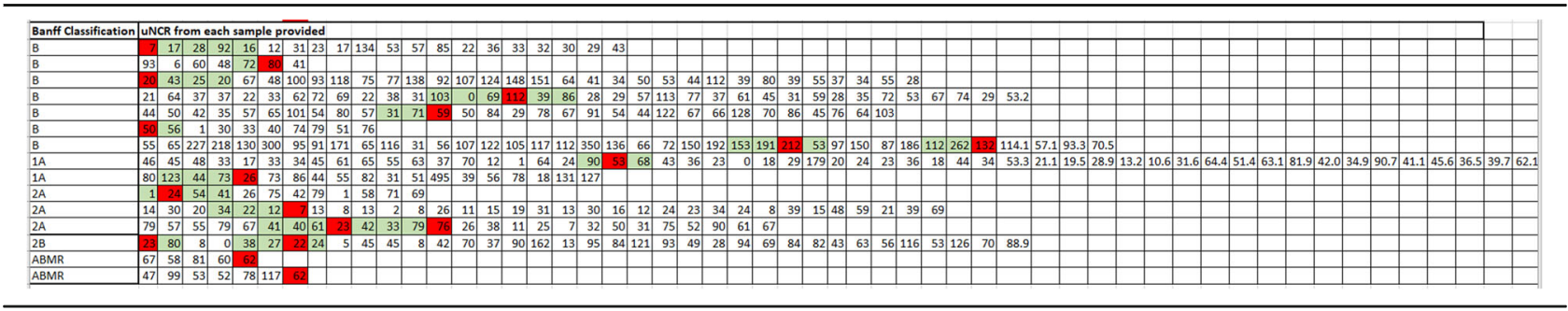

nitrate. Given that tacrolimus could reduce iNOS expression, the enzyme used to generate NO during inflammation, it is possible that tacrolimus treatment contributes to that lack of rise in urinary nitrate in transplant rejection. Although the immunosuppression regime is not stated within Smith et al's study [4], tacrolimus was only approved by the US Food and Drug Administration for prevention of renal transplant rejection in 1997 [20], a year after Smith et al's [4] original study was published. In Smith et al's [5] second study the use of ciclosporin is mentioned but not tacrolimus. The difference in the use of tacrolimus in the present and previous studies may contribute to the urinary nitrate concentrations being lower in our patients.

There are other important differences between our study and previous works. In the first Smith et al. [4] study, all of the patients were hospitalised and in the second [5] all samples were given within 90 days of transplantation. These circumstances are different to that of the well outpatient setting used in our study and may be associated with states of increased inflammation and increased iNOS expression.

Finally, at 55 years the mean age of our patient group is older than both Smith et al. [4, 5] and Mugge et al's [8] studies $(45,45,49$ respectively). Given the age difference it is more likely that this is a more co-morbid population and represents the more liberal approach to transplantation in the U.K. now compared with the 1990's. Disease states such as hypertension and cardiovascular disease as well as inflammatory conditions could all be affecting iNOS expression and nitrate concentrations. In addition, it has previously been shown

Table 5 Results for immunosuppression sub-groups

\begin{tabular}{|c|c|c|c|c|c|}
\hline & & Routine & Biopsy proven rejection & Biopsy proven No rejection & Other callbacks \\
\hline \multirow[t]{4}{*}{ Tacrolimus alone } & No. & 60 & 5 & 4 & 17 \\
\hline & $\%$ & 36.58 & 33.33 & 33.33 & 34 \\
\hline & Median & 53.31 & 26.29 & 59.99 & 47.01 \\
\hline & IQR & $38.4-81.1$ & $19.9-35.1$ & $21.66-168$ & $26.7-74.99$ \\
\hline \multirow[t]{4}{*}{ Tacrolimus \& Mycophenolate } & No. & 76 & 9 & 6 & 27 \\
\hline & $\%$ & 46.34 & 60 & 50 & 54 \\
\hline & Median & 56.85 & 49.65 & 53.43 & 41.66 \\
\hline & IQR & $36.6-89.6$ & $23.98-87.91$ & $39.54-86.93$ & 24-93.01 \\
\hline \multirow[t]{4}{*}{ Mycophenolate alone } & No. & 7 & 1 & 1 & 1 \\
\hline & $\%$ & 4.26 & 6.66 & 8.33 & 2 \\
\hline & Median & 62.49 & 61.84 & 0.73 & 30.61 \\
\hline & IQR & $27.44-72.63$ & 0 & 0 & 0 \\
\hline \multirow[t]{4}{*}{ Neither } & No. & 21 & 0 & 1 & $3^{*}$ \\
\hline & $\%$ & 12.80 & 0 & 8.33 & 6 \\
\hline & Median & 50.77 & 0 & 0.11 & 43.89 \\
\hline & IQR & $33.91-60.19$ & 0 & 0. & $40.27-53.39$ \\
\hline
\end{tabular}

* = additional 2 patients had unknown data on immunosuppressive medications 
that eNOS diminishes with age $[21,22]$. It is not clear whether this would be clinically relevant in inflammatory states such as transplant rejection.

Our data have to be considered in context of its limitations. The number with biopsy proven rejection is small at 15. Furthermore, the most common Banff rejection grade diagnosed is borderline (7 cases) with few displaying more advanced stages of rejection (Table 4). The earliest that a patient was recruited post transplantation was day 6 and therefore we have no data from D0-5 post renal transplantation.

In summary, we have measured urinary nitrate concentration in renal transplant recipients using a method which could be applied to the clinically urgent setting of transplant rejection. In contrast to historical studies we have shown urinary nitrate concentration is not a useful biomarker for renal transplant rejection.

\section{Conclusion}

Measurement of urinary nitrate concentration does not assist in the diagnosis of renal transplant rejection. Research should continue to focus on other more promising biomarkers to support the decisionmaking process around the earlier diagnosis of kidney transplant rejection.

\section{Abbreviations}

UNCR: Urinary nitrate: creatinine ratio; iNOS: Inducible nitric oxide synthase; NO: Nitric oxide

\section{Acknowledgements}

We wish to thank Karen Steer and Lynette Puddicombe for their extensive work in identifying participants and sample collection.

The NIHR Exeter Clinical Research Facility is a partnership between the University of Exeter Medical School College of Medicine and Health, and Royal Devon and Exeter NHS Foundation Trust. This project and ACS are supported by the National Institute for Health Research (NIHR) Exeter Clinical Research Facility. The views expressed are those of the author(s) and not necessarily those of the NIHR or the Department of Health and Social Care. We are grateful to Dr. Obi Ukoumunne at the University of Exeter for statistical advice.

Data from this work was presented at the Nephrology Dialysis

Transplantation Congress June 2020 [23].

\section{Authors' contributions}

AR, ACS and MG Study design and implementation, data collection, analysis and manuscript writing. JK design and implementation of sampling protocol, data collection, sample processing and quality control. MS sample analysis. PGW Methodology and discussion. BK \& LR design and implementation of recruitment strategy. All authors have read and approved the manuscript.

\section{Funding}

We thank the Mason Medical Research Trust for supporting this work. Funding was provided for research nurse time, technician time, and laboratory skills and consumables for processing the samples.

\section{Availability of data and materials}

The datasets generated and analysed during the current study are available to access in the Royal Devon and Exeter Tissue Bank (RDETB) repository, (https://exetercrfnihr.org/about/rde-tissue-bank/) through application to, and approval from, the RDETB Steering Committee (see website for details).

\section{Ethics approval and consent to participate}

Recruitment and sample collection was facilitated through the Royal Devon and Exeter Tissue Bank (RDETB), NIHR Exeter Clinical Research Facility. This is an ethically approved tissue bank, approved by the South Central - Oxford C Research Ethics Committee (REC reference number 16/SC/0162). It was set up to collect and store "spare" tissue available at the time of routine procedures. Its purpose is to support research into the mechanisms, initiation and progression of common diseases. As part of the overall RDETB project approval, responsibility for individual project specific approvals has been delegated to the RDETB Steering Committee, who approved the current project om 15/3/2017 (study codes CTB38/STB42). Fully informed written consent was obtained from all participants.

\section{Consent for publication}

Not applicable.

\section{Competing interests}

The authors declare that they have no competing interests.

\section{Author details}

${ }^{1}$ Institute of Biomedical and Clinical Sciences, University of Exeter, and NIHR Exeter Clinical Research Facility, Exeter, Devon, UK. ${ }^{2}$ Royal Devon and Exeter NHS Trust, Exeter, UK

Received: 19 June 2020 Accepted: 9 October 2020

Published online: 20 October 2020

\section{References}

1. Parajuli S, Aziz F, Garg N, Panzer SE, Joachim E, Muth B, Mohamed M, et al. Histopathological characteristics and causes of kidney graft failure in the current era of immunosuppression. World J Transplant. 2019;9(6):123-33.

2. Nankivell B, Agrawal N, Sharma A, Taverniti A, P'Ng C, Shingde M, Wong G, Chapman J. The clinical and pathological significance of borderline T cellmediated rejection. Am J Transplant. 2019 May;19(5):1452-63.

3. Haas M, Loupy A, Lefaucheur C, Roufosse C, Glotz D, Seron D, Nankivell BJ, Halloran PF, et al. The Banff 2017 kidney meeting report: revised diagnostic criteria for chronic active T cell-mediated rejection, antibody-mediated rejection, and prospects for integrative endpoints for next generation clinical trials. Am J Transplant. 2018;18(2):293-307.

4. Smith SD, Wheeler MA, Zhang R, Weiss ED, Lorber MI, Sessa WC, Weiss RM. Nitric oxide synthase induction with renal transplant rejection or infection. Kidney Int. 1996;50:2088-93.

5. Smith SD, Wheeler MA, Lorber MI, Weiss RM. Temporal changes of cytokines and nitric oxide products in urine from renal transplant patients. Kidney Int. 2000;58:829-37.

6. Ellis G, Adatia I, Yazdanpanah M, Makela SK. Nitrite and nitrate analyses: a clinical biochemistry perspective. Clin Biochem. 1998;31:195-220.

7. Khanafer A, Ilham MA, Namagondlu GS, Janzic A, Sikas N, Smith D, Griffiths D, Chavez R, Asderakis A. Increased nitric oxide production during acute rejection in kidney transplantation: a useful marker to aid in the diagnosis of rejection. Transplantation. 2007;84(5):580-6.

8. Mugge A, Kurucay S, Boger RH, Bode-Boger SM, Schafers HJ, Wahlers T, et al. Urinary nitrate excretion is increased in cardiac transplanted patients with acute graft rejection. Clin Transpl. 1996;10:298-305.

9. Tsikas D, Gutzi FM, Rossa S, Bauer H, Neumann C, Dockendorff K, Sandmann J, Frolich JC. Measurement of nitrite and nitrate in biological fluids by gas chromatography-mass spectrometry and by the griess assay: problems with the greiss assay - solutions by gas chromatography-mass spectrometry. Anal Biochem. 1997;244(2):208-20.

10. Miranda KM, Espey MG, Wink DA. A rapid, simple spectrophotometric method for simultaneous detection of nitrate and nitrite. Nitric Oxide. 2001; 5:62-71.

11. Smallwood M, Ble A, Melzer D, Winyard P, Benjamin N, Shore AC, Gilchrist M. Relationship between urinary nitrate excretion and blood pressure in the InChianti cohort. Am J Hypertension. 2017;30(7):707-12.

12. Leslie G, Cook BS, Valorie L, Chiasson BS, Mitchell B. Tacrolimus reduces nitric oxide synthase function by binding to FKBP rather than by its calcineurin effect. Kidney Int. 2009;75(7):719-26.

13. Bogossian H, Frommeyer G, Ninios I, Bandorski D, Seyfarth M, Matzaroglou C, Lemke B, Eckardt L, Zarse M, Kafchitsas K. Expression of NO synthase under medication with cyclosporin a, Mycophenolate Mofetil, and 
tacrolimus during development of transplant vasculopathy on rat cardiac allograft. Cardiovasc Ther. 2016;34:183-90.

14. Pannala AS, Mani AR, Spencer JP, Skinner V, Bruckdorfer KR, Moore KP, Riceevans CA. The effect of dietary nitrate on salivary, plasma, and urinary nitrate metabolism in humans. Free Radic Biol Med. 2003;34:576-84.

15. Wagner DA, Schultz DS, Deen WM, Young VR, Tannenbaum SR. Metabolic fate of an oral dose of $15 \mathrm{~N}$-labeled nitrate in humans: effect of diet supplementation with ascorbic acid. Cancer Res. 1983;43:1921-5.

16. Eqberts J, Soederhuizen W. Urine samples before dinner are preferable when studying changes in endogenous nitrate production under uncontrolled dietary conditions. Clin Chim Acta. 1996;254:141-8.

17. Williams JK, Smallwood MJ, Benjamin N, D'souza RJ, Shore AC, Winyard PG, Gilchrist M. Renal nitrate clearance in chronic kidney disease. Nitric Oxide. 2020;97:16-9.

18. Waikar SS, Sabbisetti VS, Bonventre JV. Normalisation of urinary biomarkers to creatinine during changes in glomerular filtration rate. Kidney Int. 2010; 78(5):486-94.

19. Melichar B, Karlicek R, Tichy M. Increased urinary nitrate excretion in inflammatory bowel disease. Eur J Clin Chem Clin Biochem. 1994;32:3-4.

20. US Food and Drug Administration, 2019, "FDA approved drugs, Tacrolimus" Accessed 6/8/20. https://www.accessdata.fda.gov/scripts/cder/daf/index. $\mathrm{cfm}$ ?event=overview. . rocess\&App $\mid \mathrm{No}=050708$.

21. Lyons D, Roy S, Patel M, Benjamin N, Swift CG. Impaired nitric oxidemediated vasodilation and total body nitric oxide production in healthy old age. Clin Sci. 1997;93:519-25.

22. Sverdlov A, Ngo D, Chan W, Chirkov Y, Horowitz J. Aging of the nitric oxide system: are we as old as our NO? J Am Heart Assoc. 2014;3:e000973.

23. Riddell A, Kirkwood J, Smallwood M, Winyard P, Knight B, Steer K.

Puddicombe L, Romanczuk L, Shore A, Gilchrist M. Can the urinary nitrate to creatinine ratio be used as a marker for kidney transplant rejection? Nephrol Dialysis Transpl. 2020;35(supplement 3):gfaa142.P1612.

\section{Publisher's Note}

Springer Nature remains neutral with regard to jurisdictional claims in published maps and institutional affiliations.

Ready to submit your research? Choose BMC and benefit from:

- fast, convenient online submission

- thorough peer review by experienced researchers in your field

- rapid publication on acceptance

- support for research data, including large and complex data types

- gold Open Access which fosters wider collaboration and increased citations

- maximum visibility for your research: over $100 \mathrm{M}$ website views per year

At $\mathrm{BMC}$, research is always in progress.

Learn more biomedcentral.com/submissions 